\title{
The Potential Of Public Media: A Case Study of Reimagine CBC
}

\author{
Tara Mahoney * \\ School of Communication, Simon Fraser University
}

\section{Introduction}

In the spring of 2014, the Canadian Broadcasting Corporation (CBC) announced that it will cut 657 positions and get out of the business of airing professional sports, a pillar of its programming for more than 60 years. As part of a plan to confront a $\$ 130$-million revenue shortfall projected for the 2014-15 broadcast year, the cuts represent about 8 per cent of the broadcaster's total work force, compensating for lower ratings and an industry-wide slump in the TV ad market (Houpt \& Simon, 2014). Viewed by some as a sign of the imminent collapse and possible restructuring of the CBC (Rowland, 2013), the sidelining of the public service mandate (in favor of the commercial mandate for ratings and profit) offers an opportunity to reimagine what public service media means.

In a sociopolitical context of unprecedented disengagement from traditional political organizations, eroding faith in modernist institutions, growing individualism, and neo-liberal globalization (Bastedo, Chu, Hilderman \& Turcotte, 2011, p. 2), this paper explores how the CBC could do more than simply reporting on events, but rather compelling and engaging citizens to act together in decisions about public media. Through a "public sphere" lens, I explore how the possibility of resituating citizens as active participants in the direction of the CBC can help facilitate a more public society by dismantling some of the traditional dichotomies between private and public life, institutional and non-institutional action, and political and social realms.

Using the Reimagine CBC project as a case study, this paper is an effort to encourage open innovation between the CBC and citizens in order to manifest new directions for public media in Canada. Given Canada's image as a highly technologically advanced nation ${ }^{1}$, open innovation provides a particularly relevant strategic direction for the $\mathrm{CBC}$, considering the increasing role of the Internet user in a "participatory culture, which is transforming value systems, undermining notions of authority, and creating rhizomatic pathways for autonomous innovation" (Draper, 2008, p. 137).

\section{Public Media, Public Society}

Public sphere theorist Jürgen Habermas argues that with the rise of late capitalism, citizens are susceptible to becoming passive consumers of goods, services, political administration, and spectacle. He suggests that neglecting a more participatory approach, public opinion may shift from debate, discussion, and reflection (what he refers to as communicative action) to the manufactured opinion of polls and spin (Habermas, 1989, p. 5). In his view, the public sphere has been colonized as relationships are increasingly mediated by money and power, and entrenched political parties and interest groups substitute for participatory democracy. A related phenomenon, referred to by Hannah Arendt as "the rise of the social", is the tendency within Western cultures to privilege private, internal life at the expense of a shared public world (Arendt, 1958, pp. 38-50). Arendt worried that "the rise of the social" symbolizes a new way of relating to the world characterized by thoughtlessness, routine, and an abiding normalization that is simultaneously misunderstood as individuation. The

\footnotetext{
* The author is a co-founder of Gen Why Media, and was directly involved in the Reimagine CBC project.

${ }^{1}$ Canadians rank first in the world when it comes to Internet usage, spending an average of 45 hours per month online (Canadian Internet Registration Authority, 2013). In addition, 40 per cent of Canadians have used a community or social networking site and almost a quarter do so weekly (Zamaria \& Fletcher, 2008).
} 
realm of "the social" cripples the sphere of action and is associated with ideas of behavior, not action (Poyntz, 2011, p. 23).

Facing a direct and constant threat from capitalist forces that seek to exploit the commercial potential of media (McChesney, 1999, p. 46), the CBC will continue to struggle to find a distinctive voice in an increasingly fragmented, corporatized media environment unless it can offer what private broadcasters cannot: public media positioned as a facilitator of a "public society". American critical sociologist C. Wright Mills explored how the power elites in society use the culture industries and the media to manipulate mass society into passivity. He sketched the difference between a "public society" and a "mass society" in terms of the characteristic forms of communication found in each. In a public society, the archetype of communication is a conversation between equals where "virtually as many people express opinions as receive them" (Mills, 1956, p. 302). . A public can translate its opinions into effective action. It can change policy as its opinions change. In a mass society, however, there is little or no opportunity for individuals to answer back. As the institutions of modernity like public broadcasting crumble in the face of neoliberal globalization (McChesney, 1999, p. 46), providing a space for the public to help shape the direction of the CBC offers citizens the chance to self-identify as something other than merely media audiences. As such, the public sphere does not begin and end when media content reaches an audience; this is but one step in larger communication and cultural chains that include how the media output is received, made sense of and utilized by citizens (Dahlgren, 2006, p. 274).

Similarly, Peter Dahlgren's (2006, p. 268) concept of the "cultural turn" in political orientation, combines notions of civic agency derived from political science and political communication within the horizons of cultural theory, cultural studies and popular culture. The "cultural turn" employs a radical democratic view of the public sphere by contending that one individual can encompass several (even contradictory) political positions at a particular point in time by virtue of multiple group identities or memberships. This emphasis on difference and highlighting tensions requires new ways of framing social reality that "de-naturalize" conventional perceptions and entrenched ideological positions (Dahlgren, 2006, p. 267). The formation of new publics requiring new communicative strategies takes as its starting point the notion of citizens as social agents, and it asks what the cultural factors are behind such agency (or its absence). The key here is to underscore the procedural and contextual dimension: the political and politics are not simply given, but are constructed via word and deed (Dahlgren, 2005, p. 159).

In the context of the "cultural turn", the CBC could ask itself: how do we use cultural and media production to put the "public" back into "public broadcasting"? Gassmann and Enkel (2004) define open innovation as the cooperative creation of ideas and applications outside of the boundaries of any single organization. In the broadest sense, citizen participation, like open innovation, seeks involvement on the part of users, audiences, and "thinkers" as a means for augmenting the perspectives found inside an organization or group. Writing about the origin of "good" ideas, Steven Johnson (2010) notes that: "...we are often better served by connecting ideas than we are by protecting them.... Good ideas want to reinvent themselves by crossing conceptual borders" (p.22). Johnson proposes that progress most often comes from the relentless probing of what can be done with combining and recombining what is known, something he calls the "adjacent possible." He writes: "Good ideas are not conjured out of thin air; they are built out of a collection of existing parts, the composition of which expands (and, occasionally, contracts) over time" (Johnson, 2010, p. 35). In regard to citizen participation, Johnson's "good ideas" come not from sitting "around in glorious isolation", but from bringing more ideas into the mix (Seltzer \& Mahmoudi, 2012, p. 6). 


\section{Reimagine CBC}

In late January 2012, the Conservative government was set to cut the CBC's 1.1 billion dollar budget by $10 \%$. This was considered to be crippling to the operations of the organization and sparked a major strategic review of both internal and external operational strategies (Casey, 2012).

In reaction to the devastating budget cuts, the Canadian Media Guild, a union of 4,500 CBC employees, approached netroots engagement organization Openmedia looking to galvanize support for the CBC. Rather than a traditional public advocacy campaign, Openmedia proposed an open and participatory engagement strategy that invited the public to offer their ideas for the direction of the CBC and, in the process, mobilize interest around public media in Canada. Openmedia then invited two other engagement organizations, Leadnow.ca and Gen Why Media, to collaborate on realizing the vision of Reimagine CBC.

The stated objective of Reimagine $\mathrm{CBC}$ on the website was:

"To ignite a national conversation to reimagine the role of public media in the age of participation, develop a crowd-sourced plan to enable the CBC to take on a leadership position in the digital era, enable the CBC to delve deeper into exploring online tools and web-inspired practices for collaboration, civic engagement, conversation, innovation and new forms of storytelling."

Over the ten-month duration of the project, the major milestones were as follows:

- 36,479 people signed an online petition opposing severe cuts to the CBC;

- 496 ideas were submitted by the public (and rated) in the Online Ideas Forum;

- 1500 people attended the "Reimagine CBC Celebration" on May 7th, 2014;

- 10,940 people participated in the public survey, created from the top-ranked ideas from the Ideas Forum (Yeo \& Trusz, 2012, p. 4).

The data and input collected from the engagement activities was organized into a crowd-sourced policy reform report detailing five citizen-driven recommendations of how to innovate the CBC for the digital age:

1) Focus on more courageous reporting; with in-depth, uniquely Canadian content that holds powerful interests accountable.

2) Prioritize radio. Canadians who believe in public media think radio provides the best value for each dollar invested, and should not be cut in favor of more expensive TV.

3) Enrich the digital ecosystem with the best content from CBC's past and present, freeing the CBC archives and bringing television and radio online.

4) Collaborate with the right partners: those who have deep roots in community, and can help CBC tell authentic local stories.

5) Use open and participatory processes to help shape a vision for the future of the $\mathrm{CBC}$, and to create an active community who supports that vision (Yeo \& Trusz, 2011, pp. 4-5).

\section{Outcomes}

After the report was released, the CBC invited Reimagine CBC director Reilly Yeo to the CBC headquarters in Toronto to give a lunch-and-learn to various departments about the process and findings of the report. Given the CBC's closed-door decision-making process, it is difficult to know what impact the Reimagine $\mathrm{CBC}$ report and project had on the direction of the CBC. 
Representatives from the Canadian Radio and Television Commission (CRTC) said that the Reimagine CBC project was a "guidepost" and "case study" for how to make media policy, and that it enriched the process of navigating policy for the future of Canadian public media (Yeo \&Trusz, 2011). A year after publishing the Reimagine CBC report, the CRTC, a notoriously bureaucratic and closed institution, changed its public consultation processes. We cannot prove this was a result of the Reimagine CBC campaign but we can speculate, as the CRTC's new engagement process bears many similarities to the Reimagine CBC process: "In the past, the CRTC engaged Canadians through public forums and written mail. With the vast majority of Canadians owning a mobile device, this consultation required a wider reach of engagement and the CRTC decided to implement an online forum to allow citizens to share their ideas" (OPIN website).

In 2013, the CRTC launched a public engagement campaign about the future of television and continued to demonstrate a change in tone with regard to public feedback: "We are very interested in receiving your views on what's on TV, how it is being delivered to you and whether you have enough information to decide what you want and how to get it. We encourage you to get together and discuss these issues and let us know what you think in any way you like -- hold a meeting, get together for coffee or join others on your local community television channel. You can then send us the results by email, in a video, or in a report, as informal as you want" (Canadians Radio and Television Commission, n.d.).

\section{Challenges}

The Reimagine CBC project faced significant challenges and limitations. Money and time constraints clashed with the ambitiousness of the enterprise. Facing entrenched institutions and well-financed opponents, it could be argued that the traditional dichotomies that Reimagine CBC attempted to dismantle were reassembled shortly after the campaign, or were never really dismantled in the first place. Although there are indications that some of the recommendations in the report have been adopted by the CBC and CRTC, the extent to which the campaign was actually politically threatening, provoked a political reprisal, or inspired institutional adoption of the core recommendations is not clear.

In addition to this, long-standing structural barriers and complex conditions made the revitalization of public media a tremendously challenging task. The main barriers included: the antagonistic orientation of neo-liberal governments puts the organization in a defensive crouch, making it challenging for the institution to take risks or make necessary changes to operations or decision making processes (Raboy, 1990, p. 15); reliance on traditional broadcast revenue models make it difficult to address the service needs of a web-based audience (Raboy, 2006, p. 305), making it harder to compete with leaner and more nimble web-based revenue models; the decision-making at the CBC is largely top down, opaque, and does not have clear mechanisms to incorporate citizen input (Skene, 1993, p. 5); The power and level of concentration of big telecommunications and media conglomerates restrain the opportunities available to the CBC; some have gone so far as to make highly publicized claims that the $\mathrm{CBC}$ should not be allowed to compete with their services given their public funding (McChesney, 1999, p. 46).

\section{Learnings}

The seemingly insurmountable difficulties facing the CBC further illuminate the need to re-situate grassroots support around a new approach. Reimagine CBC offers some preliminary insights into reinvigorating support for the $\mathrm{CBC}$ through culturally driven public participation:

1) Utilize open and transparent public participation as an alternative to closed door, top-down decision-making. In order to enable as many Canadians to participate in the project as possible, 
Reimagine CBC was open to any user with an email address. Participants were highly encouraged to respond to the question "What is your idea to make the CBC a leader in participatory, creative and engaging media?" Creating space to openly discuss problems, then communicate potential solutions avoided the often negative and even bitter public conversations that often revolve around the CBC (Yeo \& Trusz, 2012). Reimagine CBC acted as a convener and facilitator of cultural community processes, designed not only "to inform, enlighten and entertain" but also to establish new collective identities around the public broadcaster (Carty, 2011, p. 157).

2) Function as a social, cultural, political and pedagogical device by giving participants an easy way to make choices about a complex issue while providing people with the knowledge to act meaningfully. By using the Internet to coordinate diverse publics, Reimagine CBC encompassed interpersonal networks of discussion and idea generation that created spaces for construction and democratic negotiation (Kahn \& Kellner, 2003, p. 304). The public was encouraged to create and share their own op-eds, videos, articles, photos, memes, infographics, questions, quizzes, and polls (Yeo \& Trusz, 2012) describing how they would reimagine the CBC. These were used as prominent communication tools by the campaign to reflect participation back to the community. The ideas, discussions and comments were then used to write the final policy recommendation report.

3) Combine virtual social relations in cyberspace with face-to-face interactions by providing a platform to organize and engage their networks. Reimagine CBC led people "up the ladder of engagement" by starting with an easy entry point, like signing a petition or sharing an image, and gradually offered them deeper opportunities for engagement. Participants could connect with others online to organize face-to-face discussions about the future of the $\mathrm{CBC}$ with a facilitation guide provided by Reimagine CBC. Participants could also to download a "local action toolkit" and receive key updates about how to participate in actions leading up to the government's decision on the cuts to the CBC. The kit provided step-by-step instructions on how to spread the word about the budget legislation (Bill C-60) and its potential impact on the independence of the CBC. It also included a poster and local posting instructions as well as a letter-to-editor template to contact local media and instructions for joining the Reimagine CBC social media team. Mobilizing and organizing became more accessible to new and existing CBC supporters who may not have considered themselves politically engaged. It called for coalitions based on affinity, culture, contingency, and mobile positioning: using what is shared in common at a particular time and setting (Carty, 2011, p. 159).

4) Harness strong affiliations to mobilize existing supporters and attract new supporters. Reimagine CBC took advantage of the broad range of loosely affiliated networks interested in the CBC and welcomed their part-time participation in the project. The project reached out to Canadian cultural leaders with a fan base like Wade Davis (author and National Geographic photographer), Dan Mangan (musician), Ivan Coyote (author and poet), Nettie Wild (filmmaker) and Hey Rosetta! (Indie band) and asked them to join the discussion and share their unique perspectives on how to reimagine and revitalize the CBC. The project also reached out to the mainstream and independent media around a shared sense of opportunity to reshape what the public broadcaster meant to mediasphere in Canada. This led to widespread coverage and discussion on the topic across several outlets like the Toronto Star, the Tyee, the Georgia Straight and the Globe and Mail. The Toronto Star even volunteered to host its own national conversation and created a special website called "The Network" - "a national discussion forum about the CBC and what public broadcasting means to Canadians" (Himelfarb, 2012).

5) Allow for organizational flexibility and efficiency in order to follow through on policy recommendations. Early in the process the campaign reached out to the president of the $\mathrm{CBC}$, Herbert Lacoix, for his public endorsement of the process. He responded with an encouraging letter of support, which was used to leverage internal decision-making after the Reimagine CBC engagement process was over. The data collected from the engagement activities was organized into a crowdsourced policy reform report detailing recommendations of how to innovate the CBC for the digital age, based on the ideas submitted by the Canadian public. The report was made available online 
and given directly to decision-makers at Canada's telecom authority, the CRTC, Heritage Minister James Moore, the entire Heritage Committee, CBC's Board of Directors and President, and journalists who cover the CBC. Supporters of Reimagine CBC were also encouraged to share the report with their networks and send it to government offices and newsrooms across the country (Yeo \& Trusz, 2012).

\section{Conclusion}

In the absence of a participatory approach, we risk creating increasingly private niches of activity and identity at the expense of a shared public society. In his book The Public and its Problems, philosopher John Dewey (1927) argues that the key to restructuring public life is to be found in improving methods of communication. Dewey believed that the reason citizens are ill-equipped to intelligently perform public functions is because they have been unable to identify, much less cultivate, democratic habits that are learned only in open communication (Kadlec, 2007, p. 94). As an institution mandated to serve the public interest, the CBC must improve its methods of communication to determine what the public interest is.

In spite of its shortcomings, Reimagine CBC demonstrated how fostering a culture of open innovation could provide effective methodologies for engagement in public media - combining networked communication with face-to-face communities (Carty, 2010). Looking ahead, opportunities for the $\mathrm{CBC}$ to nurture open innovation are abundant: introducing social wiki software as a means to identify the concerns of the community (Lih, 2004); establishing deeper partnerships between the CBC and universities to produce political and cultural media (Hermida\&Ash, 2010); operationalizing the notion of e-commons through collaborations between the $\mathrm{CBC}$, the federal government, and citizens (Bélanger, 2005). These examples, along with Reimagine CBC, point to exciting possibilities for public media in Canada.

\section{References}

Arendt, H. (1958). The Human Condition (2nd ed.).Chicago: University of Chicago Press.

Bastedo, H., Chu, W., Hilderman, J., Turcotte, A. (2011). The realoutsiders: Political disengaged views on politics and democracy. Samara DemocracyReports. Retrieved from http://www.samaracanada.com

Bélanger, P. C. \&Andrecheck, P. (2005). “CBC'selectronic radio 3: Connecting with the elusive youth”, Journal of Radio \& Audio Media, 12(1), 120-135.

Bohman, J. (1996) Public deliberation: Pluralism, complexity and democracy. Cambridge, MA: MIT Press.

Canadian Internet Registration Authority (2013). Report: CA Factbook. Retrieved fromhttp://www.cira.ca/factbook/2013/index.html

Canadians Radio and Television Commission (n.d.). Website. Retrieved from http://www.crtc.gc.ca

Casey, L. (2012, April 4). CBC announces major cuts, plans to shed 650 jobs over 3 years.Toronto Star. Retrieved from: http://www.thestar.com

Carty, Victoria (2010). "New information communication technologies and grassroots mobilization".Information, Communication \& Society 13(2), 155-173.

Dahlgren, P. (2003) "Reconfiguring Civic Culture in the New Media Milieu”, in J. Corner and D. Pels (eds) Media and the Restyling of Politics, pp. 151-70.London: Sage.

Dahlgren, P. (2005) "The Internet, Public Spheres and Political Communication:

Dispersion and Deliberation", Political Communication 22(2): 147-62.

Dahlgren P (2006) "Doing citizenship: The cultural origins of civic agency in the public sphere" European Journal of Cultural Studies 9(3): 267-86.

Dewey, J. (1927). The public and its problems. Denver: Swallow. 
Draper, P. (2008) Music two-point-zero: music, technology and digital independence. Journal of Music, Technology \& Education1(2/3), 137-152.

Gassmann, 0, \& Ellen E. (2004). Towards a theory of open innovation: Three core process archetypes. Proceedings of the RADMA conference.

Habermas, J. (1989). The structural transformation of the public sphere: An inquiry into a category of bourgeois society. Cambridge, MASS: MIT Press

Hermida, Alfred. (2010) E-democracy remixed: Learning from the BBC'saction network and the shift from a static commons to a participatory multiplex.eJournal of eDemocracy and Open Government, 2(2), $119-130$.

Hermida, A.\&Ash, A. (2010) Wikifying the CBC: Reimagining the remit of public service media.International Symposium on Online Journalism, University of Texas, Austin, April 2010.

Himelfarb, J. (2012, March 23). The network: Fixing the CBC. Toronto Star. Retrieved from: http://www.thestar.com

Houpt, S. (2014, April 10).CBC cuts 657 jobs, reduces programs. The Globe and Mail. Retrieved from: http://www.theglobeandmail.com

Johnson, S. (2010) Wheregood ideas come from: The natural history of innovation. New York: Riverhead Books.

Kadlec A. (2007). Dewey'scritical pragmatism.Lanham, MD: Lexington Books.

Kahn, R. \&Kellner, D. (2003) Internet communication and oppositional politics, in D. Muggleton\& R. Weinzierl (eds.), The post subcultures reader (pp. 299-314). Oxford: Berg Publishers.

Kohn, M. (2000). "Language, power, persuasion: Toward a critique of deliberative democracy", Constellations7(3), 408-29.

Lih, A. (2004). The foundations of participatory journalism and the Wikipedia project.Conference paper for the Association for Education in Journalism and Mass Communications Communication Technology and Policy Division, Toronto, Canada August 7, 2004.

McChesney, R. W. (1999). Graham spry and the future of public broadcasting.Canadian Journal of Communication, 24(1), 25-47.

Mills, C. W. (. W. (1956). The Power Elite. New York: Oxford University Press.

OPIN website. Retrived from: http://opin.ca/case-study/wireless-code-consultation

Poyntz, S. R. (2011). "Hannah Arendt: Public Action, Sociality and Permanence in the World”. J. Hannan (Ed.), Philosophical Profiles in the Theory of Communication. New York, NY: Peter Lang Publishers.

Raboy, M. (2006). The 2005 graham spry memorial lecture making media: Creating the conditions for communication in the public good.Canadian Journal of Communication, 31(2), 289-306.

Raboy, M. (1990).Missed opportunities: The story of Canada'sbroadcasting policy. Montreal: McGillQueen's University Press.

Rowland, W. (2013). Saving the CBC: Balancing profit and public service. Westmount, QC: Linda Leith Pub.

Skene, W. (1993). Fade to black: A requiem for the CBC. Vancouver, BC: Douglas \& McIntyre.

Seltzer, E. \&Mahmoudi, D. (2012).Citizen participation, Open innovation, and crowdsourcing: Challenges and opportunities for planning". Journal of Planning Literature, 28(1), 3-18.

Yeo, R. \&Trusz, D. (2012). Reimagine CBC report.Retrieved from: http://reimaginecbc.ca/

Zamaria, C.\&Fletcher, F. (2007). Canada online! The Internet, media and emerging technologies: Uses, attitudes, trends and international comparisons. Toronto: Canadian Internet Project. 


\section{About the Author}

Tara Mahoney is PhD student at School of Communication, Simon Fraser University. Before completing her master degree in media production from Ryerson University, Tara worked in the nonprofit sector as Community Outreach Coordinator for a non-profit film school, Pull Focus and campaigned for the Sierra Club of Canada and Greenpeace at their Headquarters in Washington D.C. She is Creative Director and co-founder of Gen Why Media, and was directly involved in the Reimagine CBC Project. 